\title{
Forecasting Career-And Competence Indicators of a Social Worker in the Context of Digital Transformations of the Society
}

\author{
Mariia Kuzmina ${ }^{1}$, Viktor Kuzmin ${ }^{1}$, Yurii Mosaiev $^{2}$, Natalia Karpenko ${ }^{1 *}$ and Kyryl Tarasenko ${ }^{1}$ \\ 1“Zaporizhzhia Polytechnic” National University, 69063 Zaporizhzhia, Ukraine \\ ${ }^{2}$ Municipal Institution of Higher Education "Khortytsia National Educational and Rehabilitation Academy" of Zaporizhzhia Regional \\ Council, 69000 Zaporizhzhia, Ukraine
}

\begin{abstract}
The article is devoted to the problem of forecasting the career and competence indicators of a social worker in the context of digital transformations of the society. The paper analyzes the social and historical context of the formation of social workers' career competence indicators. The article compares the analogue and digital system of career competence indicators of a social worker.
\end{abstract}

\section{Introduction}

Career indicators of a social worker, like any specialist in various spheres of social existence, directly depend on the professional and life competencies they have acquired. As the competences have already been acquired, the person has the opportunity to implement them in the sphere of his/her own professional activities. Taking into consideration that nowadays there exists a practice of uniting professional and other aspects of life, so the process of living combines the mentioned above aspects in one discourse. Taking into account the specific character of social work which includes both social and practical activity as well as its historical peculiarities we can outline the necessity of investigating career and competence indicators and predicting its modifications. The specific character of Ukrainian society and other societies of the modern world is that the process of digital transformation is becoming more and more active.

The aim of the article is to investigate the process and peculiarities of forecasting career and competence indicators of a social worker in the context of digital transformations of the society.

\section{Research methods}

The basis of research includes general scientific methods such as induction, deduction, extrapolation and others. Method of sociological modeling has been used according to algorithms of structural functionalism, integral sociology of P. Sorokin, elements of the theory of social conflicts of R. Darendorf in order to analyze the forecasting of career and competence indicators of a social worker in the context of digital transformation of society. Method of social and mental assessments has been used to study the national peculiarities of the formation of career and competence indicators of a social worker.

\section{Theoretical aspects of forecasting career and competence indicators of a social worker}

Social work is a relatively new area of social activity. In spite of the fact that it traces its history since ancient times, its formation started in the beginning of the XXth century, exactly when Mary Richmond presented namely a professional approach to social work. It was she who managed to formulate and implement the first technologies and protocols of practical social work as well as work out its theoretical basis [1]. Every textbook and monograph on the History and Theory of Social work contains at least one chapter devoted to this outstanding woman, but it should be taken into consideration that the methodology of social work was based then mainly on Psychology, Social Pedagogics, Pedagogics, Defectology, Sociology etc. This situation is caused by the fact that social work was formed as a multiparadigmal sphere of practical activity aimed at providing social assistance and social services for the people who appeared to be in difficult life circumstances

In addition, one should keep in mind that appropriate methodology of social work as a scientific discipline was formed much later on [2]. Only after that social work was formed as an appropriate scientific and academic discipline and the field of practical activity. It should be emphasized that social work was based on charity, and in many countries of the world, social work as a professional activity was based namely on the basis of individual charity of patrons [3]. In countries with dominant protestant traditions, the philosophy of social responsibility of business has become the basis for the formation of an organized social assistance system.

The bright example is the activity of Andrew Carnegie aimed at developing this philosophy [4]. All 
these facts indicate that the formation of social work as a scientific discipline and sphere of practical activity did not happen systematically but even sometimes chaotically. That is why there were no specialists who would be systematically engaged in providing social assistance as people started to organize and implement social work and household social assistance at the bidding of the heart. All of this shows, however, that the main competencies of the first social workers were empathy and personal interest in spreading humanism and principles of mutual assistance. All these factors caused that the formation of social assistance and social service system all over the world was held according to the principles which did not suit the formation of professional competencies of social workers, especially since the issue of forecasting these professional competencies was not actual yet.

Under the notion "career" we mean social and labor relations of an individual throughout his/her life. In the context of social work, a special feature of a career is the high level of social responsibility and empathy of participants of the social process. A special feature of a career in the context of social work is that the career growth process is not obvious due to updating changes of social problems, and a social worker is highly likely to need retraining, which can lead to horizontal social mobility and even to a decrease of social status.

Carried out analysis demonstrates there is no universal and generally accepted interpretation of the notion "career". At the same time there is no universal conceptual content of this notion. The change in the general approach to this notion in its conceptual sense has happened within the period of time: we mean a transition from the concept "career which leads to the promotion in the professional sphere" to the concept "life is a career". This of course influences the researchers' approach. Thus, Ukrainian and Russian sociologists define "career" and "career strategy" as moving up the ladder, first in the professional sphere, and then in life in general, while western scientists define career movement as moving in a vertical straight line.Taken into account this feature, E. Shane has developed a classification system for career strategies, which is used by most sociologists in the world and is generally accepted. Taking into account this system of classifications and certain features, we conclude that the conceptual essence of a career strategy is mainly the choice of an individual aimed at success in professional activities and in life in general.

The conceptual content of the notion "career", which is relatively new in Sociology, is not clearly defined, although the problem of career has already been reflected as an object for consideration. Taking into account the definitions of the concepts "career" and "career strategies" proposed by sociologists, we can determine the conceptual essence of these concepts. The analysis of scientific publications and scientific works on this topic makes possible to characterize the term "career" in a conceptual sense, clearing out two vectors of its reception: the first one is formed on the basis of definitions proposed by the classics of Sociology, and characterizes it as a process of professional growth, which determines the general need for self-development and self-improvement; the second one is defined by the majority of sociologists of the XXth century, life is a career, it is an uninterrupted process in a certain direction of professional and personal growth [5].

If we take into account the social portrait of the first social worker, we can observe a gender and age disproportion in this aspect. Gender disproportion and dysfunction is connected with the fact that in the late XIXth and early XXth centuries, a social vector to a high level of empathy among women and a social demand for their participation in charitable activities was the mainstream. The mentioned above social vectors and social demands in the middle of the XXth century turned into social stereotypes that have not yet been overcome in the most developed countries of the world yet, not to mention the countries with a lower level of development. In addition to the gender disproportion one could easily observe an age disbalance among the first social workers. Social work included mainly younger and older employees. It can be easily explained that that the two mentioned above categories of the population showed the highest level of empathy. Young people showed it because of the so called "youth maximalism" and humanitarian education, and older people because of the desire to compensate the low level of empathy in the period an active professional career.

Overcoming the conscientious lack of professionalism of social workers and their involvement in the social service system began after the monopolization of the sphere of social assistance and social services by the state. In the 20 s of the XXth century this tendency occurred in many countries of the world, especially in countries that have chosen the socialist and paternalistic ways of developing the social sphere. In countries mentioned above, instead of social work, they increased the development of active social policy, providing at the legislative level revolutionary changes in the field of providing social standards by ensuring the right to maternity leave, an eight-hour working day and leave with financial support [6]. In this situation, social work became more and more bureaucratic, which led in the countries of the socialist vector to the total bureaucratization of all spheres of social assistance activities in future, meanwhile, a prototype of the system for predicting career and competence indicators of a social worker were implemented. Due to the lack of digital infrastructure, we will consider this stage as analogue one.

Under analogue format of forecasting careercompetence indicators of a social worker, we consider the formation of career-competence indicators of a social worker by analogues of the development of (socio)political and (socio)economic processes of social being and the main trends in the professional engagement and interaction between social institutions within a particular society.

The important element in the formation of professional competencies of a social worker is the model of social policy which dominates in this or that 
country. For the countries with a dominant social democratic model of social policy (Germany, Austria, Denmark), it is accepted to form the competencies of social workers based on solidarity, solidarism, social responsibility and a high level of personal empathy. In the context of the Anglo-Saxon model of social work (Great Britain, USA, Australia), it is accepted to form the competencies of a social worker based on the principles of updating the problems of a specific social problem and specific professionalism within a particular sphere of social services. Meanwhile for the Latin model of social work (Italy, Spain and Portugal) it is normal to base on Catholic religious ethics, religious solidarity and the principles of the social state.

The main features of the analogue format of career and competence indicators of a social worker are as follows:

- Implementation of instructions of the state leadership and local governments as a counterbalance to the needs of people who find themselves in situations of extreme difficulties. Namely this factor has led to a low level of trust to a particular social worker and social work in general in many countries of the world. Within the framework of authoritative and totalitarian regimes, social workers have become full-rate agents of the antipopular system. That is why in countries where the above mentioned principle dominated, people were mostly unwilling to use social services and to deal with specific social workers in general;

- The high level of formalism and lack of flexibility in the work of a social worker with a specific case led to the fact that the act of helping a particular person or family has turned into a small bureaucratic operation, which appeared to be an imitation of the providing of social services or social assistance. As a result, the domination of this analogue feature of career and competence indicators of a social worker leads to low efficiency of both his specific activity and the social service system as a whole;

- Differentiation of contact with a specific person regarding the age, gender, and social status of the client. This analogue factor was that the client's achievements for the country, state system, or gender and even age could lead to social inequality of social service clients to the social worker, who could provide high - quality social assistance for certain clients, while others were deprived of it. For example, in the USSR, better social assistance was provided for veterans of World War II and socialist labor. And it happened both in the sphere of social assistance and social protection. It became particularly visible in the field of Health Improvement and the possibility of getting rare goods and services firstly.

The examples of individual analogue career and competence indicators of a social worker indicate the inefficiency and non-objective character of social workers' activities stimulated in some countries. Of course, this factor in the activities of social workers in developed countries of Europe and North America differed much from the social sphere in countries with authoritarian and totalitarian regimes, but it also had a lot of drawbacks. Therefore, positive changes in the system of the analogue system of career and competence indicators of a social worker started with changes within the framework of the "person-state" system. These changes became possible due to theoretical developments of the French School of postmodernism and, in particular, the works of $\mathrm{M}$. Foucault, who proclaimed the deconstruction of traditional knowledge and the transition from their rational forms to emotional ones [7].

It was the verystage which was marked in the Humanities and social sphere as a stage when interpretation dominated formal content. So if taken in the paradygm of an analogue organization of social work, a social worker was a specialist who formally provided a particular form of social assistance, that means the professional competencies of a social worker were reduced to a step-by step application of certain regulations in this area. This form of analogue competence was characteristic not only for social work, but also for other spheres of social being and professional activity.

That is why in the paradigm of French postmodernism [7], the possibility to interpret not only situations from their everyday life and to make decisions based on their own competencies was offered to each individual person. But in this case they got the same opportunity. This situation was familiar to social workers either. It was the time when the idea of forecasting and forming professional competencies of both social workers and representatives of other specialtiesstarted its formation. The main reason for this state of affairs was the situation of the beginning of a rational attitude to stuff politics both at state-owned enterprises in the countries of the socialist vector and at private enterprises in the countries of the capitalist world. Of course, this trend was current for the social sphere. This led to a new wave of volunteers. People began to trust social institutions and institutions more, and they began to show a high level of empathy for people who found themselves in difficult situation, making this project either independently or together with representatives of social institutions, with social workers directly.

Later on the possibility of social workers in their activities became flexible and began to depend in some aspects on the level of emotional intelligence. This category means the ability to express emotions and perceive the emotions of others [8]. Namely in the early 80 s of the XXth emotional intelligence became one of the leading competencies of a social worker. Since passive empathy has already existed and required increased emotionality according to the trend of social development in Western civilization, and therefore today social workers should have a high level of emotional intelligence. Since there is a high level of emotionality and the ability to develop ones own emotional intelligence and the colleagues'emotional intelligence and people who are in trouble. Modern psychological and sociological concepts consider emotional intelligence as an important universal lifeand-professional competence that makes possible to 
establish communication in your professional activities and personal life.

\section{Practical aspects of forecasting career and competence indicators of a social worker in the context of digital transformations of the society}

Forecasting the career and competence indicators of a social worker gained its significance in the context of digital transformation. Over the past 30years total digital changes have become a strong tendency and they are, unfortunately, can't be observed in Ukrainian social work. At the same time, it is impossible to tell about the high level of implementation of new technologies into the social sphere of other countries, and is not only Ukrainian burning issue, but also has a regional context at least.

The 90s of the XXth century contributed much to the professional competencies of social workers: the so called office-competences were added to the list. Due to the fact that social work in any country has never been a highly paid profession, and therefore this sector mainly includes people over middle and (before) retirement age. Therefore, in the era of information technologies, social workers have not been able to master these skills due to age-related difficulties and lack of information culture. If we consider Ukrainian realities, we can draw attention to the fact that Ukrainian society missed the global information transformation which took place in the early 90s. Our country was engaged in the restructuring of social processes and the majority of the actively young generation did not integrate into the Information Society, which was founded in North America and Europe.

So in the 90s, there was only a tendency to develop the information society as well as system social programming both at the interregional, national and regional levels, and already in the middle of the first decade of the XXI century, both Ukrainian society and the social sphere found themselves in a situation where all social groups except young people were not integrated to the global level of it. This allowed young people to take advantage of a number of social ladders that allowed them to increase their social status by means of professional implementation. At the same time, this trend has not developed in the social sphere yet. Since young people did not evaluate the prospects for the development of the social sphere as a sphere of professional implementation, and the lack of basic equipment for the implementation of these skills until the middle of the first decade of the XXth century led to the fact that the older generation of social workers did not want to implement computer competencies in practice, and the younger generation simply did not realize the perspectives and appropriate tools for it.

A particular solution to this problem was to provide computer equipment, to connect existing social workers to the network at the end of the first decade of the XXI century and to organize trainings for the stuff of social institutions and social services. At the same time, professional requirements turned out to be minimal for social workers and were reduced to the necessity to use office programs, print out text documents and simple tables. So, most Ukrainian social workers in the second decade of the XXI century aqiured only computer skills at the level of an office worker of a commercial company of the late 90 s of the XXth century. Though ideally, their skills should have been extended to the level of primitive programming of local network products for the social sphere and developing or updating mobile content for various social service clients. Surely, social workers would not have to become full-rate programmers, but their professional skills could contribute to the formation of software and mobile applications if provided a developed information culture and appropriate information ecosystem within the social sphere. Social workers from different social institutions could have formed a request for appropriate software products. If such a system had been functioning for the past two decades and this would have created a number of relevant IT professional competencies for social workers. It is also important to ensure the formation of a highly effective culture among social workers. It is proposed to use motive the game in adapting new social personnel and in building a workflow for employees [9].

If all the mentioned above had been implemented, so we would have the following results now:

- The professional skills of an ordinary social worker would include computer skills which could be higher than that of an ordinary office worker due to the existence of global, local and regional computer specialized networks that social workers would use to create standard documents in the sphere of assessing the quality of social work technologies with different groups of social service clients, depending on circumstances;

- Appropriate resources and algorithms would be created to test, aprobate and modernize existing methods of social work. Moreover, in all the years of Ukrainian independence, many topic related conferences, seminars, round tables and other analogue scientific events are held, where various topical issues for the social sphere are still being constantly discussed. But practically, the problems we have mentioned have hardly been updated in this sense. This shows, however, that social specialists had a large number of current organizational problems and the topic of creating network resources to make a full-rate information "community" has never been actual for them. The situation has not changed later on, at the beginning of the second decade of the XXI century, whatever social sphere could be chosen;

- Total information system development at the beginning of the XXI century was expected to initiate the formation of a request for programming social processes in order to solve the problems of specific people who appeared to be in difficult life circumstances. Although social workers could be actively involved in the process, this problem is actual 
in the research by Bulgarian scientists Venelin Terziev and Magip Georgiev, they raise and update this problem both at the national and European levels [10]. Without updating this problem today, social work as a whole and specialists who ensure its functioning may find themselves out of actual social processes taking place in modern Ukrainian society and cease to be in demand in modern and postmodern innovative social practices. This disfunction will finally lead to the marginalization of social work of both social practices and institutions, as well as individual specialists involved in its functioning;

- The era of mobile applications continued the total information-developing of social processes, and social workers, due to the importance of their own specialty to ensure the harmonious development of society, should have been the first to master it. Due to the fact that this social aspect has not been implemented, as a result, today there are dozens of mobile applications in the smartphone of every Ukrainian that can help a person learn a foreign language, order a taxi, food, communicate with friends and relatives, but at the same time there is no way to get social services or at least to consult about it. This state of affairs indicates brightly the lack of a system for forming professional skills of social workers in the field of Information Technology.

The analysis is of advanced pedagogical experience has shown a wide range of research in the system of development and formation of students' competence. It has demonstrated that the formation of students ' competence happens under the influence of a number of factors and reasons among which practical training is quite important. It is shown that implementation of practical training tools by teachers in the educational process will improve the professional training of students in accordance with the requirements of the labour market and potential employers. Analysis and assessment of practical results of the formation of students' competence by means of practical training have demonstrated a number of trends. Thus, the analysis of the results of the PISA-program which has been worked out by the Organization for Economic Cooperation and Development (OECD) showed the highest indicators of the average score in Mathematics, Reading and Science in Austria, Belgium and Germany, compared to the average score in the OECD countries. It was found that the average score of students in Mathematics in Ukraine in 2018 is 21 points lower than the average score in the OECD countries, Reading is 36 points lower, and Science is 20 points lower. Analysing the dynamics of students, who get higher education in the EU member states in general and in German-speaking countries in particular, the tendency for increasing of this indicator has occured. Thus, in 2018, compared to 2015, the number of students in Belgium, Luxembourg and Germany increased significantly $(2.09 \%, 2.09 \%$ and $4.80 \%$ accordingly), while in the EU member states the growth was only $1.65 \%$. Analysis of the dynamics of changes in the number of students as a percentage of the population aged 20-24 years in German-speaking countries showed the highest level of students getting higher education among the population in Belgium aged 20-24 [11].

Nowadays one of the options for improving the situation in this area would be the way of implementing optional courses for the students (social work), who will be engaged in creating mobile applications, or at least establishing links between students and young specialists in the field of social work and technical specialties, especially in the areas of programming, system analysis etc. Of course, this will not lead to their becoming programming specialists in future, but it will create a common interdisciplinary field that will expand the horizons of social workers in the information sphere and programming. In the longperspective, this would give a significant increase in the technical competencies of social workers. This system would be especially effective if employers set social workers the task not only to acquire such knowledge and competencies, but also to encourage social workers with financial support. Due to the lack of it in this area and the lack of appropriate knowledge, such competencies are hardly to be found among social workers.

One of the options for spreading technical and informational skills among social workers is to create social worker positions in social services with the skills of a technical administrator and a social network worker. It may seem that the first position is not relevant due to the existence of such a position in social services, which is replaced by professional programmers or technical specialists. Our idea is to replace these specialists with social workers with technical or programming skills. This replacement should take place due to the fact that technical workers fulfill this work in a standard way without taking into account the specifics of the social sphere.

On the one hand, it may seem that the technical specifics should not differ within the social sphere and, for example, administrative management, but a technical worker with the skills of a social worker has the ability to adjust all technical settings not only according to technical protocols, but also according to the logic of the development of social processes that occur in society and trends in the development of the social sphere. The problem under consideration is relevant because today we need to involve social workers in creating new mobile applications. It would be aimed at consulting and providing social assistance in a smartphone. And today this is a time requirement that may become not up-to date, as mobile applications are developing rapidly, and neither in Ukraine nor in the vast majority of countries of the world has not developed appropriate mobile applications yet, but even a concept on this issue hasn't been formulated.

In our opinion the main concept of creating mobile applications for social services can be expressed to the following items:

1. These mobile apps must be created in cooperation between mobile application programming specialists and social workers. This cooperation should combine the experience of programmers and practical 
social workers in order to better develop and continue their functioning. Realising namely this aim, training courses and educational programs in the field of social work should provide acquiring competencies in system analysis, programming theory and, surely, visualization of information and educational products.

2. In addition to the main aim, mobile applications must have a pedagogical component. According to Kh. Tangirov, mobile applications and other information technologies play one of the most important roles in the modern educational process and their potential is far from being totally used [12]. Mobile applications related to the functioning of social services with different groups of clients should include both informational and educational materials. That is why social workers should develop competencies in training important skills among social service clients that will help them overcome difficult life circumstances in their lives. In general, onlineconsultations and teaching skills in the same form enable practical social workers to make their work interactive and up-to-date.

3. Taking into account the fact that many social workers during their studies in higher education institutions mostly received theoretical knowledge and did not have the opportunity to test their knowledge in practice, so in order to avoid this case, social workers should be given a task that contains the necessity for practical skills [11]. Despite certain educational drawbacks, future and current social workers take full responsibility for the lack of sufficient practice. Since it often happens that social workers, learning mostly theory, do not show initiative in the field of obtaining additional practical training. This process can be divided into two phases. The first one is when future social workers, while taking introductory, training, industrial, professional and other types of practice, are not interested in gaining practical experience themselves, as they want to get functional responsibilities that are as simple as possible to perform and do not require enough time to complete. This cognitive position affects the overall competence negatively.

So, the lack of a social worker's constant desire to improve not only by learning theoretical knowledge, but also by mastering practical knowledge is a negative sign and not a desire to work efficiently. Another way to avoid the opportunity to learn new knowledge is simply absence of desire to learn more, including also practice.

4. The problem mentioned above is typical both for social work students and for practical social workers with appropriate education and experience in social services and other institutions providing social services. In this case, there is a problem of lack of necessary professional competencies among young social workers who are starting their professional career and social workers who, due to the peculiarities of their own professional activities, could not get professional competencies that are vitally important for their work. In our opinion, this problem can only be solved by simulating specific cases of providing social assistance and social services. To fulfill it, one need to create appropriate social motivation, such as stimulants for airplane pilots and medical stimulants, which are based on communication with virtual patients. For most young social workers, such a form of mastering professional competencies would be very useful as it is common in form and resembles a game, and may even be a full-rate mobile game with its own character (Fig. 1).

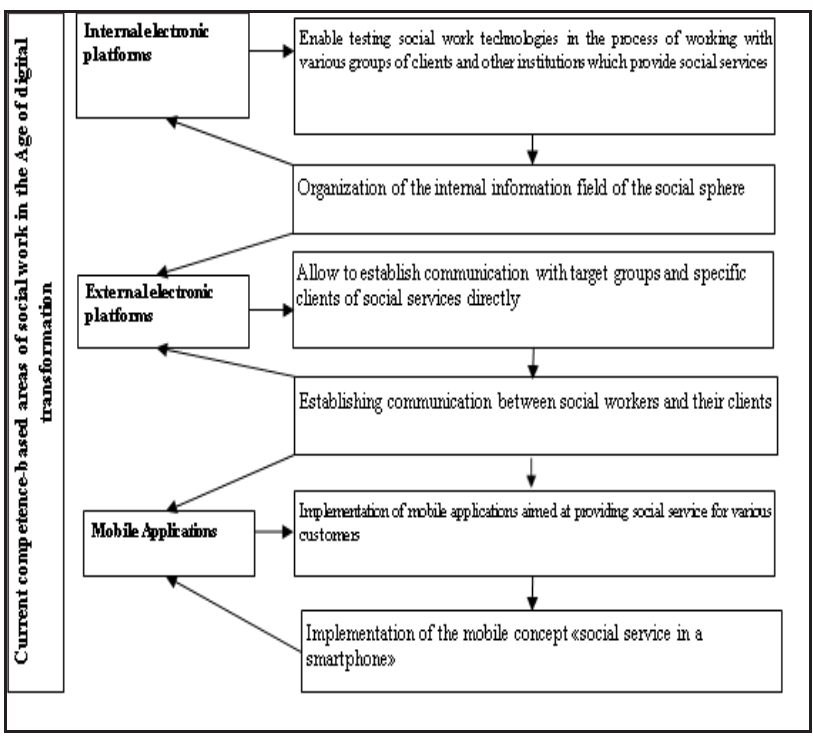

Fig. 1. The concept of creating mobile applications devoted to social services activities in the Age of digital transformation

From a practical point of view, it promotes the creation of game content on mobile devices devoted to social services and the formation of an innovative set of visualizations of the most common effective social practices that are important for a person to overcome certain social difficulties. Nowadays, we can assure that there are some existing examples of such social content in the world, but we also realize the high probability of its updating. This state of affairs gives us the opportunity to predict that for the implementation of such projects, such competencies of a social worker as the need to create positive ways out from difficult life circumstances by using of certain technologies of social work. In addition, a social worker must independently or by cooperating with his colleagues predict the probability of a positive or negative result of using a particular technique based on the peculiarities of the difficult life situation in the life of a particular person.

Nowadays in order to form the students' competence in the academic process it is necessary for the teachers to fully apply not only the well-known means of practical training (implementation of module educational program, forming the necessary level of theoretical basis, implementation of educational, training, pre-graduate and other kinds of practical component in the process of educating students, the usage of information, innovative and interactive technologies, training students in accordance with the requirements of the labor market and employers, 
providing cooperation between higher educational institutions within the framework of student exchange programs), but also implementing the so-called "socialservices" game content on mobile devices and the formation of an innovative complex of visualizations of the most well-known, effective social practices which are extremely important for a person to overcome life difficulties.

\section{Conclusions}

Forecasting the career and competence indicators of a social worker is an important component in the development of social work. This has become particularly important in the era of digital transformation. New information technologies are rapidly changing the social reality and setting new competence guidelines for representatives of various specialties, including social workers is very important. Modern social workers, despite the absence of clear rules and competencies, need to master them, including Information Technology and Programming, as social sphere today requires high-quality technological solutions to provide high-quality social assistance and modern social services in working with various groups of people.

\section{References}

1. M. J. Austin, Social Service Review, vol. 92, 4, (2018). doi: 10.1086/701278

2. J. Steve Hothersal, Eur. J. of Social Work, vol. 22, (2019). doi: 10.1080/13691457.2018.1499613

3. S. Mapp, J. McPherson, D. Androff, S. Gatenio Gabel, Social Work, vol. 64, ( 2019), https://doi.org/10.1093/sw/swz023

4. A. Zhulina, Performing Philanthropy from Andrew Carnegie to Bill Gates, vol. 23 (2018). doi: $10.1080 / 13528165.2018 .1533762$

5. V. V. Kuzmin, The Bull. of Y. Mudryi National Law University. Series:Philosophy, philosophies of law, political science, sociologyVol. 1 No. 48 (2021). doi: 10.21564/2075-7190.48.224813

6. A.A. Gumenyuk, Klio. 3 (87), (2014), p. 65-72

7. J, Guilhaumou, Presses Universitaires de Provence (2016), p. 267-289

8. J. Wena, Intern. J. of Hospit. Manag., vol. 81, (2019), p. 120-130

9. A. Karpenko, K. Basenko, Balt. J. of Econ. Stud. 3(4), 101-106 (2017). doi: 10.30525/2256-0742

10. K. Tangirov, Mental Enlightenment ScientificMethodological J., (2020), p. 76-84

11. M.O. Kuzmina, O.L. Protas, T.V. Fartushok, Y.M. Raievska, I.B. Ivanova, Intern. J. of Higher Educ., 9(7), (2020), p. 279-288

12. Kh. Tangirov, Didactical possibilities of mobile applications in individualization and informatization of education. Ment. Enlight. Sc.Met. J. 1, 76-84 (2020) 